\title{
sciendo
}

\section{MeAnS Against THE RULE OF NOBODY}

\section{Mirko Pečarič ${ }^{1}$}

\begin{abstract}
This paper presents means by which relations between facts and decisions can be put on a higher, more transparent and accountable level. The complexity of relations, their exponential effects, new technology and numerous rules have increased the public administration's unaccountability for its actions - if it is even possible to talk about accountability at all. This kind of situation is presented as the rule of nobody that through multiple relations, competencies and division of labour diminishes the possibility to view a situation as a whole, and enhances the distinction between a person's formal role and his inner personal world. Classical decision-making procedures (more or less still) exclude interactions between political-legal and scientific institutions on one side and between the first and social groups on the other about modern risks that go beyond classical factory-related or occupational hazards. If the presented means (performance indicators, the avoidance of exclusive subjective evidence, the use of probability in individual cases, the right to clear information, the office for legislation and regulatory analysis and an IT platform) were formally integrated into decision-making, they could enable democratisation, for which the non-stop present and available communication links are sine qua non.
\end{abstract}

\section{Keywords}

Rule of Nobody, Evidence-Based Regulation, Performance Indicators, Probability, Right to Clear Information

"It is a capital mistake to theorise before you have all the evidence. It biases the judgment" - Sherlock Holmes (Doyle, 2015, p. 22)

\section{Introduction}

An absence of a relation between facts and decisions is the eternal problem of decision-making ("Though seeing, they do not see; though hearing, they do not hear or understand"; Matthew 13:13). The latter is usually done by our everyday intuitive practice. People usually do not think about how they frame and solve problems, although they could many

\footnotetext{
${ }^{1}$ University of Ljubljana, Faculty of Administration, Gosarjeva ulica 5, 1000 Ljubljana, Slovenia. E-mail: mirko.pecaric@fu.uni-lj.si.
} 
times already be solved differently (or even recognised as wrong) with a little reflection. Decisions are often obfuscated by erroneous or incomplete analyses that use relative risks instead of absolute ones (Gigerenzer, 2003; Rifkin \& Bouwer, 2007), by heuristics and biases (Kahneman, 2013; Terje, 2003; Tversky \& Kahneman, 1974), with no real, scientific evidence that result in improvements in decisions (Hubbard, 2007, 2009), with the lack of good communication and confrontation of solutions with reliable partners (Beck, 1992; Lynch, 2009). This makes the human factor aspect of decision management sometimes heavier than its tangible and technological counterpart (Trevisani, 2007). Though personal cognitive biases are important considerations, this paper will be focused only on (un)wanted institutional biases and a lack of public deliberation that are reflected in public decision-making. When the classical (legal) decision-making procedures exclude interactions between political-legal and scientific institutions on one side and between them and social groups on the other, the result can be only a legitimation crisis. How can these exclusions be aligned with a demand that public institutions must base their decisions on evidence $?^{2}$ There is a need for different standards (to align transparency with accountability), a new agreement between science and the law that will bring them closer, i.e. enhance their interactions. This is the basic idea of this paper. From this predisposition, the paper provides some ways through which the public administration's activities ${ }^{3}$ could be taken as appropriate in the public domain. The paper addresses the above-mentioned two (un)wanted institutional biases (the low levels of interaction between [especially social] science and law and between the first and the public) ${ }^{4}$ and suggests appropriate means for their convergence. Problems and means should be administrated together, because they are the same picture. ${ }^{5}$ The paper recognises as a first cause for the institutional bias the so-called rule of nobody and/or a division between the person's outer role and his inner ethical world. The second cause is recognised to be a lack of public deliberation; a system that can analyse and evaluate public goals more objectively and efficiently should put persons closer to their statuses as citizens (especially in social fields, where "experts" usually do not know more about some social topic than ordinary citizens). Effective and legitimate public administration can exist only through its citizens. Public trust in the power holders in the public administration's activities starts and ends in democratic participation and open discourse through which all concerned have a stake in decision-making processes. Based on the description of both causes in the following chapters means are proposed for the maximisation of legitimacy to be able to talk about a unity, represented by the rule of everybody.

\footnotetext{
${ }^{2}$ Although this demand is included in the legal principles of the rule of law and legal certainty, the law cannot seek absolute certainty. As a cure against the illusion of certainty, Gigerenzer (2003) presents Franklin's law, who in 1789 wrote that "in this world nothing can be said to be certain, except death and taxes" (Franklin, 1844, p. 68) (although there is also uncertainty present about the time of death and amount of tax contributions).

${ }^{3}$ As the majority of decisions is prepared by public administration (the drafts of primary legislation and secondary legislation), a major focus will be on public administration.

${ }^{4}$ These biases are present in all laws that were prepared solely by public administrators.

${ }^{5}$ Means are not only equally important as goals, but they predispose them: "if the only tool you have is a hammer, [you will be tempted] to treat everything as if it were a nail" (Maslow, 2002, p. 15).
} 


\section{The Rule of Nobody}

Power in the ancient regime was traditionally exercised with visible fire and sword, represented by kings, knights, soldiers and tax collectors. This kind of ius imperium is today no longer executed in the same manner, but it is still present in more sophisticated forms; with regard to the latter, people (more or less) voluntarily bow and/or comply with a multitude of different rules (made in the majority of cases by the executive). Already for Rousseau, "the most absolute authority is that which penetrates into a man's inmost being and concerns itself no less with his will than with his actions" (Rousseau, 2009, p. 13). For Tocqueville, the novel features under which (new) despotism may appear in the world are based on the fact that "the will of man is not shattered, but softened, bent, and guided: men are seldom forced by it to act, but they are constantly restrained from acting: such a power does not destroy, but it prevents existence; it does not tyrannize, but it compresses, enervates, extinguishes, and stupefies a people, till each nation is reduced to be nothing better than a flock of timid and industrious animals, of which the government is the shepherd" (1996, pp. 313-314). He, similarly to Rousseau, noticed the minuscule nature of otherwise permeate and pervasive power: "it must not be forgotten that it is especially dangerous to enslave men in the minor details of life. For my part, I should be inclined to think freedom less necessary in the great things than in the little ones, if it were possible to be secure of the one without the other" (Tocqueville, 1996, p. 316).

For Weber, as the founder of the bureaucratic (legal-rational) model, one of the fundamental elements of all modern culture is "rational conduct on the basis of the idea of the calling... [which means] limitation to specialised work [that] began to dominate worldly morality. This order is now bound to the technical and economic conditions of machine production which to-day determine the lives of all the individuals who are born into this mechanism... But fate decreed that the cloak should become an iron cage" (2001, pp. 122, 123). As the "iron cage" (stahlhartes Gehäuse) traps individuals in systems through rational specialisation and details, it is no wonder that it became synonymous with the bureaucratic administration which "means fundamentally domination through knowledge. This is the feature of it which makes it specifically rational . . . every domination expresses itself and functions through administration" (Weber, 1978, pp. 225, 948). For Weber, modern officialdom works on "the principle of fixed and official jurisdictional areas... The reduction of modern office management to rules is deeply embedded in its very nature... the authority to order certain matters by decree does not entitle the bureau to regulate the matter by commands given for each case, but only to regulate the matter abstractly" (Weber, 1946, pp. 196, 198). A modern, rational bureaucracy dominates through the detailed, specialised regulations that put people in the iron frame. At pretty much the same time (in 1929), Lord Hewart named this tiny, step-by-step bureaucratic encroachment as the new despotism that "gives Parliament an anaesthetic. The strategy is different [than in the old despotism], but the goal is the same. It is to subordinate Parliament, to evade the Courts, and to render the will, or the caprice, of the Executive unfettered and supreme" (Hewart, 1929, p. 17). Nisbet has in the same manner later declared that "during the past half century the bulk of power in our society, as it affects our intellectual, economic, social, and cultural existences, has become largely invisible, a function of the 
vast infragovernment composed of bureaucracy's commissions, agencies, and departments in a myriad of areas..." What gives the new despotism its peculiar effectiveness is "its capacity for entering into the smallest details of human life" (1975).

This network of public administration and other public authorities with interconnected rules and effects - that can no longer be focused solely in a single person or authority - represents a fertile ground for avoiding accountability. To Arendt, "government by bureaucracy is government by decree, and this means that power, which in constitutional government only enforces the law, becomes the direct source of all legislation. Decrees moreover remain anonymous... and therefore seem to flow from some ruling overall power that needs no justification" (1973, p. 243). This state of affairs runs contrary to the demand whereby the impartiality and professionality of the public administration should walk hand-in-hand with transparency and accountability. If the latter two conditions are not met, the public administration meets Arendt's criteria for "the rule by Nobody" as perhaps the most formidable form of a dominion of man over man:

bureaucracy or the rule of an intricate system of bureaus in which no men, neither one nor the best, neither the few nor the many, can be held responsible, could be properly called the rule by Nobody. If in accord with traditional political thought, we identify tyranny as a government that is not held to give an account of itself, rule by Nobody is clearly the most tyrannical of all, since there is no one left who could even be asked to answer for what is being done. It is this state of affairs, making it impossible to localise responsibility and to identify the enemy, that is among the most potent causes of the current worldwide rebellious unrest, its chaotic nature, and its dangerous tendency to get out of control and to run amuck (Arendt, 1972, pp. 137-138). Bureaucracy is the form of government in which everybody is deprived of political freedom, of the power to act; for the rule by Nobody is not no-rule, and where all are equally powerless we have a tyranny without a tyrant (Arendt, 1972, p. 178).

In parliamentary coalitions, a strength of opinion many times does not depend on facts, but on the number of those with whom they are associated. Even if a consensus is achieved on a wrong solution, the latter is nevertheless de facto still wrong; consensus reached by this way merely smooths the way towards even faster and effective mistakes and their consequences. Coalition governments are (only) politically accountable as a group; they also delegate large authorizations for detailed regulations to the executive and a vicious circle is completed: there is no one with whom a decision can be directly associated. Arendt has also connected the rule by nobody with the banality of evil as the effect of the first, which she saw in Eichmann (the German officer on trial):

except for an extraordinary diligence in looking out for his personal advancement, he had no motives at all... He merely, to put the matter colloquially, never realised what he was doing. . It was sheer thoughtlessness - something by no means identical with stupidity - that predisposed him to become one of the greatest criminals of that period. And if this is "banal" and even funny, if with the best will in the world one cannot extract any diabolical or demonic profundity from Eichmann, that is still far from calling it commonplace... the essence of totalitarian government, and perhaps the nature of every bureaucracy, is to make functionaries and mere cogs in the administrative machinery out of 
men, and thus to dehumanise them. And one can debate long and profitably on the rule of Nobody, which is what the political form known as bureaucracy truly is (Arendt, 2006, p. 210).

From a collective's point of view, the same situation was described by Bauman, who placed it on the ability of modern, rational, effective, technologically advanced and routine-based, but morality-silenced, bureaucracy. ${ }^{6}$

\section{Self-emergence of the rule of nobody in multiple, intertwined connections}

The present situations of (even more numerous) multiple interconnections and layered decision-making dismantle the old Juvenal's saying sic volo, sic jubeo, stat pro ratione voluntas (thus I wish, thus I order, my will stands in place of reason): there is no clear will that could be pinned to an individual. The easiest way is to blame an individual regulator rather than to understand ways in which situations and/or conditions arise and produce a problematic outcome (Zimbardo, 2008). The traditional regulatory thinking neglects the basic system's predisposition of interconnections. Instead, it only looks towards final goals (regardless of how they are assembled) and assumes a single (of few) cause(s) rather than the multiple interrelated causations. ${ }^{7}$ The rule of nobody has fertile grounds in all cases with multiple connections, and can emerge even in otherwise acceptable principles of cooperation or integration. This rule is a result, and not a cause. This is a good thing, because a solution can be found in a different arrangement of a system. There should be more controls present over the methods used in the formation of rules, rather than over specific commands, as Hayek noticed. ${ }^{8}$ Arendt's description above of Eichmann and Bauman's modern bureaucracy fit into Zimbardo's Situation: “the bigger power for creating evil out of good [is] that of the System, the complex of powerful forces that create the Situation. A large body of evidence in social psychology supports the concept that situational power triumphs over individual power in given contexts" (Zimbardo, 2008). The network of intertwined institutions and powers, a thorough and complex system of rules, a system with no fundamental management elements, result in the even stronger rule of nobody. The "original sin" could be in those competent officers who should (but do not) ask themselves in the first place about the eligibility of certain actions. A rise of unaccountability many times begins with ordinary public servants, because they do not ask questions: Primo Levi (Italian Jewish writer and Holocaust survivor) said that "[m]onsters exist, but they are too few in number to be truly dangerous; more dangerous are the common

\footnotetext{
${ }^{6}$ The technical-administrative success of the Holocaust was due in part to the skilful utilisation of "moral sleeping pills" made available by modern bureaucracy and modern technology. The natural invisibility of causal connections in a complex system of interaction and the 'distancing' of the unsightly or morally repelling outcomes of action to the point of rendering them invisible to the actor were most prominent among them. Yet the Nazis particularly excelled in a third method, which they did not invent either, but perfected to an unprecedented degree. This was the method of making invisible the very humanity of the victims (Zygmunt Bauman, 2013, p. 27).

7 The traps of non-systems thinking lie in two simple dimensions; firstly avoiding the inevitable interconnectivity between variables - the trap of reductionism, and secondly, working on the basis of a single unquestioning perspective - the trap of dogmatism (Reynolds \& Holwell, 2010, p. 6).

${ }^{8}$ The more complex the order aimed at, the greater will be that part of the separate actions which will have to be determined by circumstances not known to those who direct the whole, and the more dependent control will be on rules rather than on specific commands (Hayek, 1998, p. 50).
} 
men, the functionaries ready to believe and to act without asking questions" (Levi, 1986). People usually do not question the facts-decisions relation, and they make (or agree with) decisions in its absence. Bauman (2009) in a functionalistic manner - due to the precise distribution of work, expertise and functions by which our time is known - presupposes that almost every action goes through a chain of people, each of which performs a small part of the universal mission. The number of people involved is so big that no one can reasonably and convincingly prove (or be accountable for) his "authorship" (a sin without the sinner). For Bauman, the code of conduct and guidelines for decision-making in the performance of a personal role do not extend to an internal "true self" which is supposedly free. After the "return" from the outer world in which others took (or assured us so) responsibility for actions, now the real responsibility is difficult to handle because of the lack of habit ("what I should do with myself to satisfy my conscience"). Too often this kind of feeling adds a bitter taste to personal uncertainty, and people really miss doing what they previously rejected - in an effort to escape loneliness and helplessness they are willing to solve their individual self by subordination to the new forms of authority or formally accepted patterns, no matter who created them or in what way. As public servants are nothing but humans (and usually no wiser than others), formally employed by some public institution, for them, as for every citizen as a reasonable person, it could be legitimate to ask: "Why should I follow this rule/demand?"

\section{Unquestionable trust in an allegedly professional administration}

Public servants many times also do not critically ask questions (themselves or others) in public administration, but with an important twist: they are not questioned due to apparent expert knowledge. On the other hand, public decisions are many times formed on the basis of guesses, randomness, without facts or information (this can be confirmed by - without a need for multiple citations - many public servants or decision-makers), but this is usually not put under question, because they could lose their authority (the same stands for science [Zehr, 2000]), or paradoxically even enhance it (by cutting the Gordian knot of uncertainty). ${ }^{9}$ Uncertainty can be presented, i.e. abused in many ways, if de facto transparency and objectivity on a larger scale are not brought into the systematic decision-making. A social role of scientific uncertainty helps us to see how many of our problems about risk are deeply cultural, and cannot be overcome simply by the application of the more and better science, like the questions of value or the prevailing cultural attitudes that frame our decision-making practices (Jamieson, 1996). When rules are ineffective or even cause unintended consequences, public institutions are under pains to legitimise their decisions based on the traditional decision-making procedures, established in the 19th century's classical industrial society, where "the logic of wealth production dominates

\footnotetext{
${ }^{9}$ Such occasions give the public administration an opportunity to impose protective decisions about the apparently endangered public values, security, peace, etc. (e.g. the precautionary principle, or in Slovenia a potential closure of national borders due to a probable wave of refugees and the empowerment of the national army with police border-control jurisdictions), which could also be (as the same result) achieved under the illusion of certainty as a tool for political and economic goals to, e.g. ban the import of "dangerous" foreign goods, and protect domestic "safe" products.
} 
the logic of risk production [while], in the risk society this relationship is reversed. The productive forces have lost their innocence in the reflexivity of modernization processes" (Beck, 1992, pp. 12-13). Modern decision-makers - despite the unmanageable uncertainty - lack two important parts to fill their decision-making procedures: (1) they (usually) do not use (or invite) scientific methodology that could equip public decisions with objectivity, and (2) do not use social or participatory dynamics of groups to give decisions more life-like vividness. "If anyone - government official, scientific expert or lay person - takes any given risk seriously, he or she must proclaim it. It must be widely publicised because people must be persuaded that the risk is real - a fuss must be made about it" (Giddens, 1998, p. 29). For public decision-makers, the basic rule of rulemaking should be enacted: in the absence of the real, objective and tested reasons authority is nothing but violence. "It is crucial to distinguish between power and violence: power is psychological, a moral force that makes people want to obey, while violence enforces obedience through physical coercion" (Žižek, 2010, p. 388). Violence thus understood bursts in the absence of systemic decision making. Only the latter can give enough information on which every grown and reasonable man can be convinced into a reasonable decision.

\section{Means against the Rule of Nobody}

In the world, in which future uncertainty can be based only on probabilities, the means by which public goals are achieved are more important than the intended goals: only with the former, can we get to the latter. And the means are a lot more than a draft decision's internal linguistic consistency. It was against this kind of imaginary coherence without real arguments (sophism) that Plato warned in Gorgias and Republic (2004; 1976) For Arendt, "[i]nner consistency of theories produces hypnotic effect of connection between reality and factuality" (1972, p. 110). Also, Hammond's correspondence theory of truth (1996) focuses on the correspondence of ideas with facts, and not on the coherence of ideas with ideas. Another problem with the correspondence of ideas with facts is that the latter can quickly change: "[k]nowledge that does not change behaviour is useless... But the knowledge that changes behaviour quickly loses its relevance. The more data we have and the better we understand history, the faster history alters its course, and the faster our knowledge becomes outdated" (Harari, 2016). Though regulatory complexity that evolves non-stop is higher than any kind of scientific approach, people should have means by which they could evaluate public decisions; in this way, we could be closer to true legitimacy and public sovereignty. So, what could these means be?

\section{The legislative footprint and clear statement of reasons for general acts}

One solution can be in the so-called "legislative footprint". The latter is usually understood as a comprehensive public record of lobbyists' influence on a piece of legislation (TI-EU, 2015), but to it should also be attached all professionals and public servants who were paid for their work (professionals through contracts or other means of payment, servants through their salaries) vis-à-vis a specific draft law. An individual administrative decision is signed by the official who issued it, and (usually) also by the official who conducted 
the proceedings and has prepared a draft decision. Why should not a draft law have the signatures of the people (professionals and public servants) who drafted it? If a draft law is put into legislative procedure through a public legislative initiative, signatures of citizens are and must be present, otherwise the initiative is not valid. Even if citizens cooperate in public deliberation about a specific draft law, their names are also recorded. Why therefore should it not be the same for public servants who make a draft law? Connected with that is also the statement of the reasons that lead to a draft law, an analysis made in a particular field, and the explanation of each article. Why an individually-adjudicated case must be fully and reasonably explained, but not draft laws (a merely "copy[Article] - paste[into an area of Article's explanation]" cannot count as a fulfilment of this obligation). The first, if wrongfully decided, affects an individual, while the second will affect many people. On this path of logical thinking, the latter should be all the more explained, not only because of its wider intrusion into people's rights, but also because of the easier, more effective and efficient implementation of the law. This can be done only if the law is clear to norms' addressees. If we recognise clarity as the part of the principle of the legal state, there should be no obstacle to present this possibility as a formal obligation.

\section{Clear focus on objectives and preferences - performance indicators}

A second solution is connected with the first (both replicate a dialogue). A solution can be present in the different regulatory techniques, focused more on the objective determination of facts in draft laws. In this frame, a good argumentation of draft laws can more easily be made if we do not want to stay in merely sophistic, although apparently well-explained frames (arguments with no objectivity are used also for fairy tales and astrological predictions). But the fact remains that when we do not know what we are doing, matters usually become worse than when we do nothing. All measurable or quantifiable variables should be carefully observed. In their absence, management does not have a basis for a determination as to whether a method is effective. As a kind of placebo effect, it can even think the method works, because the latter cost a lot of energy, resources, time, etc. An apparent consensus that stands alone like a lighthouse about a proposed or working method can be equally or even more dangerous: consensus on the wrong solution will only ensure big mistakes faster and more efficiently. For any method of prediction used, we must in a Hubbard manner ask, "How do we know it works" (2009, p. 15)? An old management saying "you cannot manage what you cannot measure" holds even in usually unthinkable places, even in marriage. ${ }^{10}$ If something cannot be measured directly, it can be indirectly through the relevant performance indicators $(P I)$. To prevent disruptions in the future, $P I$ are the components that enable/substitute dialogue (they can also include a rating system of priorities and an early-warning system with triggers). PI can help an institution to define, measure and accommodate activities that support progress toward goals. Draft laws also describe foreign legal systems about a relevant topic, and drafters use foreign examples - in a negative or positive way - to prove their point, but this is the

\footnotetext{
${ }^{10}$ In a memorable example, Dawes showed that marital stability is well predicted by a formula: frequency of lovemaking minus frequency of quarrels (Kahneman, 2013, p. 226).
} 
mistake if they are seen as good/bad per se. Other countries are different in so many ways that their examples could only illustrate a point, not prove it.

Performance indicators $(P I)$ are many times absent in legal acts; one reason for this could be in agencies' avoidance of being blamed in case of low indicators, but this kind of thinking - although it comes easily to mind as common sense - is the logical fallacy post hoc ergo propter hoc: outcomes in time really follow indicators, but the former has not been caused by the first. Decision-makers cannot use the ex-ante indicators for the ex-post outcomes. Good decisions cannot become bad, and the latter cannot become the former. ${ }^{11}$ This is always true in a given time-space frame, but it can change in different frames. Good decisions can become bad, and the latter can become the former in cases when feedbacks are not present or systemic accommodations to new contexts are not made even if there is new information available (but not used). There is a thin border between the $P I$ and good decisions: the first show objectives, preferences and outcomes, while the second enable clarity of thought and action. Outcomes (or good or bad experience) are only input for future decisions: "once the decision is made, we will not learn anything about the quality of the decision by observing its outcome. Furthermore, once the outcome is revealed, there is no point in seeing it as good or bad: it is simply the outcome, the starting point for future decisions" (Howard \& Abbas, 2015, p. 57). A systemic view on decision-making sees in a decision a predictive model that points towards future outcomes (uncertainties) with a certain degree of belief (probability), based on available objective pro et contra evidence. Updating decisions for incorporating new information can be done by using Bayes' formula, one of the most important in probability theory but one of those formulas unknown in public administration.

\section{The avoidance of exclusive subjective evidence}

To improve execution, leaders sometimes employ the TQM, Six Sigma, CAF or other methods of self-evaluation, but these methods face a cognitive error of over-confidence and/or illusory superiority. ${ }^{12}$ Most of us have a better opinion of ourselves; this could be a good psychological element to cope with ourselves, but it is not good to establish an objective state of affairs on it. Nohria, Joyce and Roberson, based on the examination of

\footnotetext{
11 This outcome-centred thinking does not help us very much in making good decisions. The decisions are made prior to observing the outcomes (Terje, 2003, pp. 96-97). There is no point in valuing an outcome after the decision is made. "The most fundamental distinction in decision analysis is the difference between the quality of a decision and the quality of its outcome. The distinction implies that we can make good decisions but still get a bad outcome due to uncertainty. Observing the outcome tells us nothing about the quality of the decision - just about the quality of the result" (Howard \& Abbas, 2015, p. 32).

12 This cognitive bias is known also as the Lake Wobegon effect. Lake Wobegon is a fictional town created by Garrison Keillor to provide the setting for the long-running radio broadcast, Prairie Home Companion. Keillor started his transmissions by saying: "Welcome to Lake Wobegon, where all the women are strong, all the men are good-looking, and all the children are above average" (A Prairie Home Companion, 2016). This effect is the result of excessive conviction in the people's own abilities; it is a well-established concept of bias, in which subjective confidence in personal decisions - regardless of their objective correctness - grows proportionally with an increasing self-confidence. This is an example of false, unsubstantiated subjective probability of an event (Dawes \& Mulford, 1996; Dunning, Griffin, Milojkovic, \& Ross, 1990).
} 
more than 200 employed management practices over a ten-year period by 160 companies, developed the $4+2$ formula for business success:

Most of the management tools and techniques we studied had no direct causal relationship to superior business performance. What does matter, it turns out, is having a strong grasp of the business basics. Without exception, companies that outperformed their industry peers excelled at what we call the four primary management practices-strategy, execution, culture, and structure. And they supplemented their great skill in those areas with a mastery of any two out of four secondary management practices-talent, innovation, leadership, and mergers and partnerships (Nitin, Joyce, \& Roberson, 2003, p. 42).

The (self-)assessment surveys are based mainly on personal opinions; they must be weighted also with objective data. As we are naturally overconfident in our capabilities, the same stands for our predictions. If results are to be used in the future, they should be based on probabilities based on statistical analysis or methods used in actuarial science. "Without an independent, objective measure of risk management, the perception of any success may merely be a kind of placebo effect" (Hubbard, 2009, p. 40). This effect can be misleading even though is based on (individual) experience: without consistent feedback on past actions, there is no reason to believe our experience will tell us something significant. If a survey were carried out in the Middle Ages on whether the Earth is flat or round, the answers would, in the majority of cases, be the first option. If a group reaches a high consensus on decisions, we are very close to a single decision-maker situation (one leading person leads all others); the importance or value of such fully subjective decision is diminished due to the lack of objective and different data. Democracy presupposes dialogue, negotiations, debate, different and contrary opinions; in this way patterns can be found/extrapolated (by, e.g. multivariate regression to build a formula that can describe how elements in a vector of variables respond simultaneously to changes in others) on which decisions can be based. This could be a direction of future research, distant from today's (only majority or binary, yes/no decisions).

\section{Use of probability in individual cases or establish an overall degree of irregularities}

The illusion of certainty has already been pointed out; there is always some level of uncertainty present. When a level of uncertainty rises, it is time to use the most appropriate mean to address it. The public regulatory institutions could in this frame use - as the scientific community does - an analytical technique known as risk analysis, that is measured with the use of probability. "When cause and effect cannot be delineated clearly, risk assessment is a way to navigate in this 'iffier' territory. The concept of risk is ... simply, a possibility. Not a sure thing, not a certainty, but something that might happen or bring about some result" (Rifkin \& Bouwer, 2007, p. 7). A well-known method of inferential statistics - but probably the least used in the public administration - is Bayes' formula (Gambrill, 2012; Holyoak \& Morrison, 2013; Jeffreys, 1998; Williamson, 2010):

$$
P(H \mid D)=\frac{P(H) P(D \mid H)}{P(H) P(D \mid H)+P(\sim H) P(D \mid \sim H)} .
$$


It relates current probability $(D \mid H$ - the degree of belief in $D$ [data] given that the proposition $H$ [hypothesis] is [ not] true) to prior probability $H$. It is a way of calculating how new information about an event changes the pre-existing expectations of how likely the event was or is. Bayes' rule specifies how one ought to update one's beliefs based on evidence; it is the fundamental principle of normative decision-making that routinely clashes with human intuition. Bayes' rule can be very simply shown as a decision tree: in defined problem settings, with defined objects having defined capacities, algorithmic procedures can solve problems (or at least put them on more objective grounds). We will not go here into the specifics of Bayes rule; the purpose here is only to point out the means, among which is also this rule. Probability can be also very good at determining the level of irregularities in the public administration. The determination of probability of numerous cases' irregularities can be presented by the statistics, i.e. probability sampling plans, random selection and representative samples as the methods for obtaining evidence. Their main advantage is the use of probability and statistical inferences on the rest of population (of people, actions, decisions) with a high degree of impartiality, accuracy, created confidence intervals and tested hypotheses. The number and relative sizes of items (sampling units) in a regulated population, the risk of error, the statistically (tolerable) rate of deviation, stratification and value-weighted selection can contribute to the relevance and reliability of evidence produced. These statistical means could give us a degree of legality in some field.

\section{A right to clear information}

It is not enough that information is only given; it also has to be clear, unambiguous and not decisive. Different interpretations of the same thing can produce drastically different results. "There is a consensus today that the public has a right to information. But there is not yet a consensus that the public also has a right to get this information in a way that is clear and not misleading" (Gigerenzer, 2003). Gigerenzer urges all associations to report risks in clear terms such as absolute risks and natural frequencies, rather than in ways that more likely to confuse people (relative, conditional and subjective risks). According to Gigerenzer (2002), instead of hard Bayesian computation which people are illiterate in, natural sampling takes place as the sequential process of updating event frequencies from experience (or written in formula as) $p(H \mid D)=A / A+B^{13}$ where the neglect of base rates is cancelled by observing frequencies. Figure 1 (Gigerenzer, 2003) shows the difference between natural frequencies and probabilities. On the left is the tree with natural frequencies that represents how a person would encounter statistical information through direct experience. On the right-hand side is the same information in Bayes probabilities:

\footnotetext{
${ }^{13}$ A foraging organism which, day after day, samples potential resources for food and learns the frequencies with which a cue (e.g. the presence of other species) predicts food performs natural sampling by updating the frequencies $a$ and $b$ from observation to observation. Natural sampling is different from systematic experimentation, in which the sample sizes (the base rates) of each treatment group are fixed in advance (Gigerenzer, 2002, p. 63).
} 
Figure 1: How natural frequencies facilitate Bayesian computations

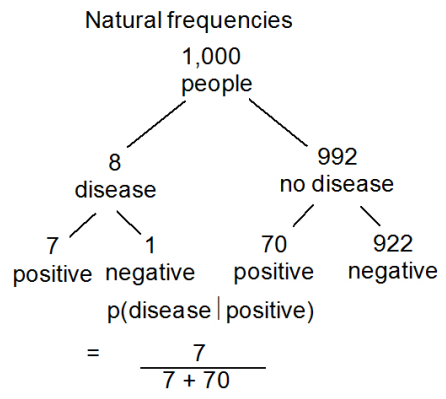

\author{
Probabilities \\ $\mathrm{p}$ (disease) $\quad=.008$ \\ $\mathrm{p}($ pos $\mid$ disease $) \quad=.90$ \\ $\mathrm{p}($ pos $\mid$ no disease $)=.07$ \\ $p($ disease $\mid$ positive $)=\quad p($ disease $) p($ positive $\mid$ disease $)$ \\ $p$ (disease) $p$ (positive disease) $+p$ (no disease) $p$ (positive $\mid$ no disease) \\ $=\frac{.008 * .90}{.008^{*} .90+.992 * .07}$
}

Relative frequencies as numbers no longer carry information about the natural base rates, because people are very prone to neglect base rates ${ }^{14}$ (that are updated from observation to observation). The same thing can be presented as a reduction of, e.g. 0.9 percent or of 22 percent. ${ }^{15}$ The latter option (relative frequencies) is used when a decision-maker wants to achieve a particular goal, and the former (absolute frequencies) when some other decision is preferred. Regulatory agencies therefore usually use relative risks to accentuate the adverse effects of exposure to contaminants (to discourage people from using some products or from exposing to their effects), while pharmaceutical and other companies use relative numbers to describe the benefits of drugs or products (to sell more); relative risks are also used in news relating to health or other risks (maybe because they result in more sensational stories that boost ratings or newspaper sales): "in all these cases, it would be wise to consider the source and be mindful of the agenda of any group that's communicating about risk. The discussion and understanding of absolute risk, relative risk, and uncertainty are essential to objective decision-making" (Rifkin \& Bouwer, 2007, p. 10). An ability to use different representations in public matters should be a matter of elaboration, analysis and deliberation; relative risks are the (although fully transparent) tool by which people can be exploited without even perceiving this fact as such.

\title{
The office for legislation and regulatory analysis
}

Risk means a probability of future events with their (good/bad) consequences or impacts. With these two elements, risk is tightly connected with the public administration, because they effect means and goals, because they have an impact on (public) objectives.

\footnotetext{
${ }^{14}$ The base rate problem means insensitivity to prior probability of outcomes and/or base-rate frequency of (average) outcomes in the relevant category. Kahneman uses an abbreviation WYSIATI for intuitive jumping to conclusions on the basis of limited evidence that means "what you see is all there is" (2013, p. 86). The base rate can be expressed also as "every information needs its representation".

${ }^{15}$ Absolute risk reduction: absolute risk reduction is the proportion of patients who die without treatment (placebo) minus those who die with treatment. Pravastatin reduces the number of people who die from 41 to 32 in 1,000. That is, the absolute risk reduction is 9 in 1,000 , which is 0.9 percent. Relative risk reduction: The relative risk reduction is the absolute risk reduction divided by the proportion of patients who die without treatment. For the present data, the relative risk reduction is 9 divided by 41 , which is 22 percent. Thus, pravastatin reduces the risk of dying by 22 percent (Gigerenzer, 2003).
} 
It is a peculiar paradox that private sector organizations apply risk analysis and risk management on a larger scale than public institutions, although the consequences are in the latter case - due to their wider implementation - usually larger. The ability to address future functionally presupposes a system of risk analysis as its key element; future uncertainties should be identified, categorised according to the degree of their harm/benefit, assessed in probabilities and communicated in a sensible, understandable way to provide the most objective decision support for the risk management's choice of arrangements and measures. This can be done at first or the most quickly in the office that usually takes care of the quality of drafting of legislation and for the equal approach to drafting of legislation, i.e. in the Office for Legislation in the Executive branch of government. Ascertaining only compliance with the constitution and the legal system, as well as with the acquis and with the technical legal rules is not sufficient (any more) for the effective and efficient administration of future. To this Office could be added a part that would conduct risk/regulatory analysis ${ }^{16}$ as a tool used for the anticipation and evaluation of likely consequences of rules. The best alternative is the one with the highest profitability, no accidents and no damage to the society as a whole (not only for a ministry's competence field). This kind of alternative should be based on the quantitative ex ante predictions and key performance measures or indicators, and the ex post assessments of risk and uncertainties over certain periods of time. Rules can address a flexible surrounding only with flexible tools that provide systemic data collection, determination of their regularly activities and web/group interactions, evaluation vis-à-vis wanted regulatory effects and feedback mechanisms towards decision-makers. Cost-benefit analysis - that is usually shown as the main regulatory analysis's element - is only one ${ }^{17}$ element among others in regulatory analysis. A predisposition for a good cost-benefit analysis is a knowable future, but the latter is always not fully knowable. The future can be better addressed with the terms "risk", "uncertainty" and "probability" that can give better support for decision-making. The challenge is (to dare ${ }^{18}$ ) to know how to describe, measure and communicate risk and uncertainty. Government offices for legislation need to identify the main factors causing risks, to the best of human ability, although this should be only one among other steps that could build risk management in a systemic way. For the latter, it is usually assumed that it is included also in governance and administration - so what is the point of new

\footnotetext{
${ }^{16}$ A regulatory analysis includes reasons for a proposed action, an examination of alternative approaches, and mainly quantitative (as well as also qualitative) evaluation of the proposed action vis-à-vis the main alternatives identified by the analysis.

${ }^{17}$ The main problem [of Cost-benefit analysis] is related to the transformation of non-economic consequences, such as (expected) loss of life and damage to the environment, to monetary values... The result is often that the cost-benefit analyses just focus on certain consequences and ignore others. As for risk analysis, the probabilistic basis for cost-benefit analysis is seldom clarified, but the classical thinking with a search for correct probability values seems to be dominant. It is common to question the validity of cost-benefit analyses because of their unrealistic assumptions about the availability of the data needed to complete the analyses. The underlying philosophy seems to be that without objective, hard data the analyses break down (Terje, 2003, pp. 39-40).

${ }^{18}$ The origin of "risk" dates from the mid-17th century: from French risque (noun), risquer (verb), from Italian risco danger and rischiare run into danger (Oxford Dictionaries, 2016). Rischiare is tightly connected with courage or bravery as the best mean between foolhardiness and cowardice. To risk is to "dare" (to know). Sapere Aude!
} 
words replacing the old ones? "Risk management provides a structured way of assessing and dealing with future uncertainty... The term 'management' implies that risks are to be treated in an ordered fashion, rather than in a haphazard way" (Cooper, Grey, Raymond, \& Walker, 2004, p. 4).

New terms emphasise the ordered organisational and material structure that permanently re-examine and re-assess (and deal with) the present and future uncertainties that can in different ways affect the achievement of public goals. The continuous monitoring, review and management of uncertainties should be the sine qua non of each public administration. One of the first steps towards the mentality of risk analysis and risk management could be the already mentioned performance and financial indicators (into a world of regulatory certainty and fully convinced decision-makers should also be added the worlds of "regulative illusionary certainty" and "brave, but careful" decision-makers). To indicators could also be added the sunshine clauses, experimental norms, etc., all the way to the Office of Legislation and Regulatory Analysis with its parallel micro units in each ministry, to ex-post evaluate regulatory effects. In all doings, places and times, care should be given to balance between the need of timely, but not fully certain action and a need of postponed, but more certain action vis-à-vis wanted goals.

\section{Administration of General Legal Acts as Systemic Management}

The means given in the previous chapter put together and a statute (general legal act) as a whole can be understood and viewed through the eyes of project management. Clients, customers and citizens are more and more demanding, and society is becoming more and more complex. More emphasis should be on the technical and personal guarantors that the statute's outcomes are really reached, or even surpass public expectations. This can be achieved if certain conditions are met. A clear statement of needs and means to provide outcomes lowers uncertainty; first of all, the statute's purpose should be unambiguous, clear, and in language understandable to all. Even before this stage, an analysis ${ }^{19}$ of the factual situation should be made and reasons given why there should be a new law at all (the efficient implementation of the law is no guarantee that its outcomes are suitable for its intended, but not clearly stated purpose). After these two phases, the statute should also clearly point to people/stakeholders who will be involved in implementation and who will provide real-time decisions in the course of implementation. The people's roles and responsibilities should be clearly defined and people consulted, so their views can be taken into account. This presupposes that processes contain all-encompassing consultation through the agreed procedures and channels also after the statute's enactment. Only good communications improve not only decision-making, but also planning in the first stage;

\footnotetext{
${ }^{19}$ The analysis helps to understand the intended statute by asking and answering questions such as: Why is the statute being started? What are its goals? What are the expected short- and long-term benefits? Who is involved in it, what are their interests? Within what kind of environment is it assumed to be implemented? What are the statute's financial limits, and what to do if they are consumed? What is the timescale and other constraints? What are the factors that are critical to its success or failure? What solutions are proposed? How much is it expected to cost and who will pay for it? Who, how and in what time frames will the statute be monitored and new external factors (and their combinations) evaluated?
} 
after this come the phases of implementation, monitoring, controlling and ending. There are numerous methods for managing project activities, but irrespective of the method used, careful attention must be given to the overall project goals (outcomes) and targets, to the identification of methods/means, the competences, roles and responsibilities of all participants, to time, and expenses. The whole process should be monitored non-stop, and feedbacks should be established in each part for the evaluation of the whole-process (not only outcomes, as they are the result of something else). To these stages should also be added (taken into account) the another or external one: the analysis of external non-stop evolving or flexible situations. The statute's purpose is not affected only by its implementation (internal risks), but also through the external risks to which it is exposed.

\section{Conclusion}

"Bad times, hard times, this is what people keep saying; but let us live well, and times shall be good. We are the times: whatever we are like, that's what the times are like."

Augustine, 2007, p. 131

Public institutions should base their decisions on more professionally obtained and analysed data. The "evidence-based" regulation should be based more on the available evidence rather than on the usual procedures of the public administration or public servants' personal preferences. The future goals and means to achieve them should be based on interpretations that do not fuel unnecessary levels of fear, but of more objectively determined or achievable hopes. If the paper starts with Sherlock Holmes and his demands for evidence that eliminates bias, its conclusion is given to Augustine's emphasis on the people who also define time: we are our own beginning and end. All our successes and failures depend on us, and the same stands for the proposed means in this paper. No listed means will do if they are not used in practice; there should be no confusion between a sign and the reality that is signified by it. The fact of only following rules, no matter how thoroughly, cannot save implementers or norms' addressees from the responsibility to do good, to be excellent. Each man in the process of finding answers to his personal question (Why should I follow?) decides which rules will be obeyed or ignored. A true choice is usually not to follow (or not) some rule, because the rule is almost never given in isolation. The true choice is rather between the different and interconnected groups of rules/demands and various authorities that enact them. Every act of obedience is always in some way the act of disobedience (effects are almost never completely the same as they were imagined by a decision-giver). It is crucial to have the means through which decisions or answers can be made or obtained in the utmost possible objective manner. The latter could bring back to a person his personal responsibility for his actions to do good to others; only in this way can s/he can be fully self-recognised as a free, autonomous person. Only this kind of person can make St. Augustine's good times. 


\section{References}

A Prairie Home Companion. (2016). A Prairie Home Companion with Garrison Keillor. Retrieved July 2, 2016, from http://prairiehome.org/.

Arendt, H. (1972). Crises of the Republic: Lying in Politics, Civil Disobedience on Violence, Thoughts on Politics, and Revolution. Harcourt Brace Jovanovich.

Arendt, H. (1973). The Origins of Totalitarianism. San Diego; New York; London: A Harvest Book.

Arendt, H. (2006). Eichmann in Jerusalem. New York, N.Y.: Penguin Classics.

Augustine, S. (2007). Essential Sermons: A Translation for the 21 Century. (B. Ramsey, Ed., E. H. O.P, Trans.). Hyde Park, N.Y: New City Press.

Bauman, Z. (2009). Postmoderna etika. (D. Jagič, Trans.). Zagreb: AGM.

Bauman, Z. (2013). Modernity and the Holocaust. Malden: John Wiley \& Sons.

Beck, U. (1992). Risk Society: Towards a New Modernity. London; Newbury Park, Calif: SAGE Publications Ltd.

Cooper, D., Grey, S., Raymond, G., \& Walker, P. (2004). Project Risk Management Guidelines: Managing Risk in Large Projects and Complex Procurements. West Sussex, England; Hoboken, NJ: Wiley.

Dawes, R. M., \& Mulford, M. (1996). The False Consensus Effect and Overconfidence: Flaws in Judgment or Flaws in How We Study Judgment? Organizational Behavior and Human Decision Processes, 65(3), 201-211. Available on https://doi.org/10.1006/obhd. 1996.0020.

Doyle, S. A. C. (2015). A Study in Scarlet. CreateSpace Independent Publishing Platform. Dunning, D., Griffin, D. W., Milojkovic, J. D., \& Ross, L. (1990). The overconfidence effect in social prediction. Journal of Personality and Social Psychology, 58(4), 568-581. Available on https://doi.org/10.1037/0022-3514.58.4.568.

Franklin, B. (1844). The Works of Benjamin Franklin. (J. Sparks, Ed.). Boston: Charles Tappan Publishers.

Gambrill, E. (2012). Critical Thinking in Clinical Practice: Improving the Quality of Judgments and Decisions. New Yersey: John Wiley \& Sons.

Giddens, A. (1998). Risk Society: the Context of British Politics. In J. Franklin (Ed.), The Politics of Risk Society. Cambridge: Polity Press.

Gigerenzer, G. (2002). Adaptive Thinking: Rationality in the Real World. New York; Oxford: Oxford University Press.

Gigerenzer, G. (2003). Reckoning with Risk: Learning to Live with Uncertainty (Kindle version). London: Penguin UK.

Hammond, K. R. (1996). Human Judgment and Social Policy: Irreducible Uncertainty, Inevitable Error, Unavoidable Injustice. Oxford University Press, USA.

Harari, Y. N. (2016). Homo Deus: A Brief History of Tomorrow (Kindle Edition). London: Random House.

Hayek, F. A. (1998). Law, Legislation and Liberty: A New Statement of the Liberal Principles of Justice and Political Economy. Routledge.

Hewart, G. H. B. (1929). The New Despotism. London: Ernest Benn Limited. 
Holyoak, K. J., \& Morrison, R. G. (2013). The Oxford Handbook of Thinking and Reasoning. New York: OUP USA.

Howard, R. A., \& Abbas, A. E. (2015). Foundations of Decision Analysis. Boston: Pearson. Hubbard, D. W. (2007). How to Measure Anything: Finding the Value of "Intangibles" in Business. Hoboken, N. J: Wiley.

Hubbard, D. W. (2009). The Failure of Risk Management: Why It's Broken and How to Fix It. Hoboken, N. J: Wiley.

Jamieson, D. (1996). Scientific Uncertainty and the Political Process. The Annals of the American Academy of Political and Social Science, 545, 35-43. Retrieved from http://www.jstor.org/stable/1047890.

Jeffreys, H. (1998). Theory of Probability (3rd edition). Oxford Oxfordshire: New York: Oxford University Press.

Kahneman, D. (2013). Thinking, Fast and Slow (Reprint edition). New York: Farrar, Straus and Giroux.

Levi, P. (1986, February 17). Primo Levi's Heartbreaking, Heroic Answers to the Most Common Questions He Was Asked About "Survival in Auschwitz". Retrieved January 27, 2017, from https://newrepublic.com/article/119959/interview-primo-levisurvival-auschwitz.

Lynch, G. S. (2009). Single Point of Failure: The 10 Essential Laws of Supply Chain Risk Management. New Jersey: John Wiley and Sons.

Maslow, A. H. (2002). The Psychology of Science: A Reconnaissance. Richmond, Ca: Maurice Bassett Publishing.

Nisbet, R. A. (1975). The New Despotism. Retrieved April 7, 2017, from https://www.commentarymagazine.com/articles/the-new-despotism/.

Nitin, N., Joyce, W., \& Roberson, B. (2003). What Really Works. Harvard Business Review, 81(7), 42-52.

Oxford Dictionaries. (2016). Risk - definition of risk in English. Retrieved December 27, 2016, from https://en.oxforddictionaries.com/definition/risk.

Plato. (2004). Gorgias. (W. Hamilton \& C. Emlyn-Jones, Trans.) (Revised ed. edition). London, New York: Penguin Classics.

Plato. (1976). Država. (J. Košar, Trans.). Ljubljana: Državna založba Slovenije.

Reynolds, M., \& Holwell, S. (2010). Systems Approaches to Managing Change: A Practical Guide: A Practical Guide. Springer Science \& Business Media.

Rifkin, E., \& Bouwer, E. (2007). The Illusion of Certainty: Health Benefits and Risks (2007 edition). New York, NY: Springer.

Rousseau, J.-J. (2009). Discourse on Political Economy and The Social Contract. (C. Betts, Trans.). Oxford: Oxford University Press.

Terje, A. (2003). Foundations of Risk Analysis: A Knowledge and Decision-Oriented Perspective. Chichester: John Wiley \& Sons.

TI-EU. (2015). EU LEGISLATIVE FOOTPRINT: What's the real influence of lobbying? Brussels: Transparency International.

Tocqueville, A. (1996). Demokracija v Ameriki II. Ljubljana: Krt. 
Trevisani, D. (2007). Regie di cambiamento. Approcci integrati alle risorse umane, allo sviluppo personale e organizzativo e al coaching. Milan: Franco Angeli Publisher.

Tversky, A., \& Kahneman, D. (1974). Judgment under Uncertainty: Heuristics and Biases. Science, 185(4157), 1124-1131. Available on https://doi.org/10.1126/science.185.4157. 1124.

Weber, M. (1946). From Max Weber: Essays in Sociology. (H. H. Gerth \& C. W. Mills, Trans.). New York: Oxford University Press.

Weber, M. (1978). Economy and Society: An Outline of Interpretive Sociology. (G. Roth \& C. Wittich, Eds.) (New Ed. edition). Berkeley, California: University of California Press. Weber, M. (2001). The Protestant Ethic and the Spirit of Capitalism. (T. Parsons, Trans.). London; New York: Routledge.

Williamson, J. (2010). In Defence of Objective Bayesianism. New York: OUP Oxford.

Zehr, S. C. (2000). Public representations of scientific uncertainty about global climate change. Public Understanding of Science, 9, 85-103. Available on https://doi.org/10.1088/ 0963-6625/9/2/301.

Zimbardo, P. G. (2008). The Lucifer Effect: Understanding How Good People Turn Evil. New York: Random House Trade Paperbacks.

Žižek, S. (2010). Living in the End Times. London; New York: Verso. 